\title{
Achievement rank affects performance and major choices in college
}

\author{
Elsner, Benjamin ; Isphording, Ingo E ; Zölitz, Ulf
}

\begin{abstract}
In this paper we study how a student's ordinal rank in a peer group affects performance and specialisation choices in university. By exploiting data with repeated random assignment of students to teaching sections, we find that a higher rank increases performance and the probability of choosing related follow-up courses and majors. We document two types of dynamic effect. First, earlier ranks are less important than later ranks. Second, responses to rank changes are asymmetric: improvements in rank raise performance, while decreases in rank have no effect. Rank effects partially operate through students' expectations about future grades.
\end{abstract}

DOI: https://doi.org/10.1093/ej/ueab034

Posted at the Zurich Open Repository and Archive, University of Zurich ZORA URL: https://doi.org/10.5167/uzh-215820

Journal Article

Published Version

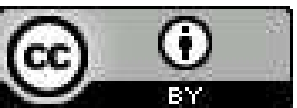

The following work is licensed under a Creative Commons: Attribution 4.0 International (CC BY 4.0) License.

Originally published at:

Elsner, Benjamin; Isphording, Ingo E; Zölitz, Ulf (2021). Achievement rank affects performance and major choices in college. Economic Journal, 131(640):3182-3206.

DOI: https://doi.org/10.1093/ej/ueab034 
The Economic Journal, 131 (November), 3182-3206 https://doi.org/10.1093/ej/ueab034 C) The Author(s) 2021. Published by Oxford University Press on behalf of Royal Economic Society. This is an Open Access article distributed under the terms of the Creative Commons Attribution License (http://creativecommons. org/licenses/by/4.0/), which permits unrestricted reuse, distribution, and reproduction in any medium, provided the original work is properly cited. Advance Access Publication Date: 27 April 2021

\title{
ACHIEVEMENT RANK AFFECTS PERFORMANCE AND MAJOR CHOICES IN COLLEGE*
}

\author{
Benjamin Elsner, Ingo E. Isphording and Ulf Zölitz
}

\begin{abstract}
In this paper we study how a student's ordinal rank in a peer group affects performance and specialisation choices in university. By exploiting data with repeated random assignment of students to teaching sections, we find that a higher rank increases performance and the probability of choosing related follow-up courses and majors. We document two types of dynamic effect. First, earlier ranks are less important than later ranks. Second, responses to rank changes are asymmetric: improvements in rank raise performance, while decreases in rank have no effect. Rank effects partially operate through students' expectations about future grades.
\end{abstract}

When making educational choices, students face considerable uncertainty. Decisions such as which college to attend or which major to choose require students to carefully assess the expected costs and benefits of each choice. Expected returns to educational choices are subjective and can be influenced by cues from a student's environment (Zafar, 2011; Stinebrickner and Stinebrickner, 2012; 2014; Wiswall and Zafar, 2015; Bobba and Frisancho, 2016). An important factor that may affect expected returns is a student's relative ability in a peer group (Marsh, 1987). Between two otherwise identical people, the person with the higher relative ability tends to be more confident and believes that she is more capable than others. ${ }^{1}$ Through this mechanism, a student's relative ability early in her career may influence her expected returns and thus affect her effort, performance and later career choices.

In this paper, we document the importance of a student's relative ability for performance and specialisation choices in university. We use data from a business school in the Netherlands in which students are repeatedly and randomly assigned to teaching sections. We measure a student's relative ability through her ordinal rank in the distribution of pre-determined achievement within a given section. To identify the causal effect of the ordinal rank, we follow Elsner and Isphording (2017) and Murphy and Weinhardt (2020) in comparing students with the same pre-determined achievement who, by chance, have different ranks in their section. The rank effect is identified through flexible controls for pre-determined achievement as well as fixed effects at the level of the peer group, through which we hold own and peer ability constant.

\footnotetext{
* Corresponding author: Ulf Zölitz, Department of Economics, University of Zurich, Schönberggasse 1, 8001 Zürich, Switzerland. Email: ulf.zoelitz@econ.uzh.ch
}

This paper was received on 26 April 2019 and accepted on 16 April 2021. The Editor was Barbara Petrongolo.

The data and codes for this paper are available on the Journal website. They were checked for their ability to reproduce the results presented in the paper. The authors were granted an exemption to publish parts of their data because access to these data is restricted. However, the authors provided a simulated or synthetic dataset that allowed the Journal to run their codes. The synthetic/simulated data and the codes for the parts subject to exemption are also available on the Journal website. They were checked for their ability to generate all tables and figures in the paper; however, the synthetic/simulated data are not designed to reproduce the same results.

We thank two anonymous referees, Alexandra de Gendre, Jan Feld and David Huffmann as well as seminar participants at Collegio Carlo Alberto, Maastricht University, Lund University, Università Cattolica, Cardiff University, EALE, ESPE and IWAEE for helpful comments and suggestions. We are particularly grateful to Arjan Non for sharing survey data with us. Maximilian Mähr provided outstanding research assistance.

${ }^{1}$ For a review of the psychological literature, see Dai and Rinn (2008). 
We document five sets of results. First, we find strong effects of a student's rank on contemporaneous performance. A one SD increase in rank reduces the risk of dropping out of the course by 2.3 percentage points while increasing the chance of passing the course by 3.2 percentage points. It also increases the grade in the respective course by $6.7 \%$ of an SD and the grade in a related follow-up course by $4 \%$ of an SD. We rule out that these results are driven by grading on a curve and show that the effects are robust to controlling for different functional forms of ability as well as adjustments for multiplicative measurement error.

Second, we document dynamic effects by exploiting the repeated random assignment of students to sections. We first show that the importance of a student's rank increases over time: earlier ranks have a smaller effect on performance than later ranks. We also show that students respond asymmetrically to positive versus negative changes in their rank. Whereas increases in the rank relative to the previous period significantly improve performance, we find no equivalent effect for decreases in rank. These results are consistent with findings on asymmetric belief updating, sometimes termed the good-news-bad-news effect, whereby people respond to positive but tend to ignore negative signals (Eil and Rao, 2011; Zimmermann, 2020). Finally, we document effects of accumulated positive and negative rank signals. Performance increases with every additional positive signal and, to a lesser degree, decreases with every additional negative signal.

Third, we show that the effect of the ordinal rank affects specialisation choices in university. A higher rank in a first-year course significantly increases the likelihood of taking a follow-up course in the same subject as well as the likelihood of graduating in a related major. Moreover, students with a higher rank are more likely to choose math-intensive elective courses. We also find a positive effect of a student's ordinal rank on the probability of graduating.

Fourth, we document gender differences in the rank effects. We find that male students react stronger to ranks than female students. This difference is particularly pronounced for specialisation choices, for which rank effects are twice as large for men compared to women. This gender difference is in line with documented gender gaps in the willingness to compete (Niederle and Vesterlund, 2007) and lower reliance of female students on within-classroom comparisons in shaping their ability beliefs (Chevalier et al., 2009).

Fifth, regarding the underlying mechanisms, we present two pieces of evidence suggesting that ordinal rank shapes student beliefs. We find that a higher rank reduces students' satisfaction with their peer-to-peer interactions. Moreover, we provide direct evidence that a higher rank increases students' expectations about their future grades. Both results suggest that a higher rank induces students to think they are more capable than their peers, shaping their beliefs about their own ability and resulting in a lower rating of peer interactions and higher expected grades.

The existing literature has established the importance of rank for a variety of outcomes. The most influential paper in this literature is Murphy and Weinhardt (2020), who showed that a student's rank in British secondary school substantially affects test scores and specialisation choices. Further studies, also based on secondary school data, document effects of ordinal rank on outcomes such as the decision to go to college and college success, risky behaviours, noncognitive skills, mental health, the choice of STEM subjects and earnings (Elsner and Isphording, 2017; 2018; Cicala et al., 2018; Denning et al., 2018; Delaney and Devereux, 2019; Pagani et al., 2019; Kiessling and Norris, 2020). Recent evidence also points to the existence of rank effects in third-level education, based on administrative data in Brazil (Ribas et al., 2020) and experimental data in the Netherlands (Bertoni and Nisticò, 2019). 
With this paper, we expand on this literature along four dimensions. ${ }^{2}$ First, in our setting, the interaction among peers is intense but short; peer groups only form for seven weeks. Unlike in most previous studies - where the same peers interact for many years-we show that even brief social interactions are sufficient to produce substantial rank effects. Given the different nature of social interactions in university, the rank effects may strongly differ from those in secondary school. Second, in our setting, students are randomly assigned to teaching sections, which allows us to rule out that students self-select into peer groups according to their expected rank. ${ }^{3}$ Third, our setting offers the unique feature of repeated random assignment to sections. We observe the same student in different peer groups and thus can exploit changes in a student's rank from period to period. This unique setting allows us to analyse dynamic effects, for example, whether students respond to changes in their rank from one teaching period to another or whether they respond differently to increases versus decreases in their rank. Finally, based on survey data, we can provide direct evidence that expectations are an important channel through which the ordinal rank affects performance and choices. ${ }^{4}$

\section{Theoretical Considerations}

There are several plausible mechanisms through which a student's ordinal rank can affect performance and career choices. A mechanism frequently documented in psychology is the effect of relative ability on a student's self-concept, often termed big-fish-in-a-little-pond effect. Numerous experiments show that students who rank highly in their peer group perceive themselves as more capable than otherwise-identical students with a lower rank (Marsh, 1987). A higher perceived ability, in turn, may translate into higher returns to effort and lead to higher performance and more ambitious career choices. A similar chain of causality can be present if the ordinal rank affects a student's motivation or self-confidence.

Another mechanism operates through a student's perceived comparative advantage. Cicala et al. (2018) theoretically showed how a student's rank may shape her perceived comparative advantage relative to her peers, which in turn may affect her effort and choices. In their model, there are two types of student, namely 'nerds', whose social status is determined by their achievements, and 'troublemakers', who derive their status from engaging in disruptive behaviour. A student with a high rank has a perceived comparative advantage in being a 'nerd', whereas the same student with a lower rank would have a perceived comparative advantage in being a 'troublemaker'. Translated into the context of specialisation choice in college, a student who has a high rank in a subject may perceive that she has a comparative advantage in that subject relative to her

\footnotetext{
${ }^{2}$ More broadly, this paper contributes to the literature on ability peer effects; see Epple and Romano (2011) and Sacerdote (2011) for reviews of the literature. The studies closest to ours are those exploiting random assignment of groups at tertiary-level institutions to estimate different types of peer effect. Examples are the experimental study by Booij et al. (2017) at the University of Amsterdam and observational studies based on data from Bocconi University (De Giorgi et al., 2010; De Giorgi and Pellizzari, 2014), Harvard Business School (Shue, 2013), the same Dutch business school as in the present paper (Feld and Zölitz, 2017) as well as military academies (Lyle, 2007; 2009; Carrell et al., 2009; 2013).

3 To the best of our knowledge, the only other study on rank effects that exploits random assignment—and the only other study looking at rank effects in university - is by Bertoni and Nisticò (2019), based on data of an experiment at the University of Amsterdam by Booij et al. (2017). Their paper's focus differs from ours by showing that rank concerns may bias traditional peer effect estimates, which in turn affects optimal class assignment policies.

${ }^{4}$ Similar evidence is provided for secondary education by Murphy and Weinhardt (2020), who used survey data to show that a higher rank improves students' confidence.
} 
peers. This perception may induce her to exert more effort, leading to higher performance and increasing the likelihood of choosing that subject as her major.

Furthermore, the ordinal rank may affect the amount of support a student receives from teachers or peers. For example, teachers may challenge highly ranked students more, which may lead to greater motivation and increased effort. Likewise, weaker students may seek help from highly ranked students, through which highly ranked students gain deeper insight into the material.

These and other mechanisms explain why it is plausible to find a reduced-form effect of a student's ordinal rank on performance and specialisation choices. In the analysis that follows, we mainly focus on the causal identification of this reduced-form effect for different types of peer group. At a later stage, we use survey data to shed light on some of the mechanisms.

\section{Institutional Setting and Data}

\subsection{Organisation of Teaching at the Business School}

We use data from a Dutch business school that offers bachelor, master and $\mathrm{PhD}$ programmes in the field of economics and business. In this section, we describe the setting and provide descriptive statistics. A similar description of the institutional details is provided in Zölitz and Feld (2020) as well as Feld and Zölitz (2017).

Our analysis focuses on the two largest study programmes. In both programmes, all first-year bachelor students follow the same general course structure and the same set of compulsory courses. Beginning in the second year, students choose from a number of elective courses and select one major. Within an academic year, there are four regular teaching periods, each lasting about seven weeks. Students typically take two courses within each teaching period and sit written exams at the end of the period. Grades range from 1 to 10 , with 10 being the highest score. The lowest passing grade is 5.5. Students can retake failed exams up to two times.

The business school's teaching and learning concept is centred on group work. While students attend lectures once or twice per week, section meetings are the main focus of their studies. These two-hour-long meetings typically take place twice a week per course. A central feature of the learning concept is that students work on the study material at home and then come together to discuss the material with their peers. The instructor, who can be a professor, lecturer, graduate student or undergraduate student, guides the discussion. This style of teaching and learning ensures that the level of student-to-student interaction is generally high.

\subsection{Sample Description}

Our estimation sample consists of five adjacent cohorts who entered the business school between 2009 and 2013. We restrict our sample in two ways. First, we focus only on the first year of the programme, which is when students are assessed exclusively by written exams at the end of each teaching period. This, together with the fact that exams are centrally graded, minimises concerns that section teachers may have a direct impact on grades and alleviates the concern that the rank effect may mechanically result from grading on a curve. Second, we restrict the sample to courses beginning with teaching period 2, dropping the very first teaching period of the first year. We do this because later, we base our rank measure on a student's pre-determined grade point average (GPA) at the start of the period. This pre-determined GPA is only available from period 2 onward, when grades from period 1 are observed. These restrictions leave us with an (C) 2021 Royal Economic Society. 
Table 1: Descriptive Statistics.

\begin{tabular}{|c|c|c|c|c|c|}
\hline & $\begin{array}{c}(1) \\
N\end{array}$ & $\begin{array}{c}(2) \\
\text { Mean }\end{array}$ & $\begin{array}{l}(3) \\
\text { SD }\end{array}$ & $\begin{array}{l}\text { (4) } \\
\text { Min }\end{array}$ & $\begin{array}{c}(5) \\
\operatorname{Max}\end{array}$ \\
\hline \multicolumn{6}{|c|}{ Panel A: student background characteristics } \\
\hline Female & 3,920 & 0.374 & 0.484 & 0 & 1 \\
\hline Dutch & 3,920 & 0.301 & 0.459 & 0 & 1 \\
\hline German & 3,920 & 0.519 & 0.5 & 0 & 1 \\
\hline Exchange student & 3,920 & 0.004 & 0.066 & 0 & 1 \\
\hline Age & 3,920 & 19.08 & 1.471 & 16.190 & 32.980 \\
\hline \multicolumn{6}{|l|}{ Panel B: student performance } \\
\hline GPA (based on past courses) & 23,526 & 6.900 & 1.310 & 2.250 & 10 \\
\hline Course dropout & 23,526 & 0.0714 & 0.258 & 0 & 1 \\
\hline Passed course & 23,526 & 0.705 & 0.456 & 0 & 1 \\
\hline Course grade & 21,846 & 6.393 & 1.686 & 1 & 10 \\
\hline Same subject follow-up course grade & 9,228 & 6.625 & 1.767 & 1 & 10 \\
\hline \multicolumn{6}{|c|}{ Panel C: student choices and longer-run outcomes } \\
\hline Taking a follow-up course & 23,526 & 0.240 & 0.427 & 0 & 1 \\
\hline Number of follow-up courses & 23,526 & 0.362 & 0.760 & 0 & 7 \\
\hline Graduating in related subject major & 23,526 & 0.490 & 0.500 & 0 & 1 \\
\hline Taking math electives & 23,526 & 0.473 & 0.499 & 0 & 1 \\
\hline Graduation & 13,629 & 0.690 & 0.463 & 0 & 1 \\
\hline Earnings & 6,283 & 42.56 & 37.85 & 0.001 & 650 \\
\hline Retrospective study satisfaction & 8,159 & 8.072 & 1.142 & 1 & 10 \\
\hline \multicolumn{6}{|c|}{ Panel D: rank variables constructed at the section level } \\
\hline Rank & 23,526 & 0.491 & 0.312 & 0 & 1 \\
\hline Rank in same-gender group & 23,456 & 0.490 & 0.341 & 0 & 1 \\
\hline Section size & 23,526 & 12.590 & 1.460 & 9 & 16 \\
\hline
\end{tabular}

Notes: Descriptive statistics of estimation sample. Earnings are in EUR 1,000. Panels B and C report outcomes at the student-course level. The number of observations for 'graduation' is lower because we set this variable as missing for all students who could not have graduated over the observed sample period. The number of observations is lower for 'Earnings' and 'Retrospective study satisfaction' as these are only observable for students who took part in the graduate survey we conducted.

estimation sample of 3,920 students and 23,526 student-course observations. A further restriction applies when we analyse graduation probabilities. Here, we avoid censoring the data by further restricting our sample to students who, given their enrolment year, could have graduated by the end of our observation period.

Table 1 displays the descriptive statistics for our estimation sample. Panel A shows studentlevel characteristics. In total, $37 \%$ of students are female. More than half of the students are German (52\%), followed by Dutch (30\%). The average age of first-year students is 19 years. Panels B and C display our main outcomes of interest. We report the summary statistics for these outcomes at the student-course level. Panel B lists indicators of student performance at the level of student-course combinations. On average, we observe each student in six first-year courses. The average student enters a course with a GPA - the average grade of all past courses — of 6.9. Around $7 \%$ of students who registered for a course drop out during the term. The average passing rate for first-year courses is $71 \%$ and the average end-of-course grade is 6.4 . In addition to students' contemporaneous performance, we also look at students' follow-up grades in the same subject. We define a follow-up grade as the next grade a student obtains in the same coursesubject cluster. Course clusters refer to groups of courses that focus on similar subjects, such as 
Microeconomics, Finance or Accounting. For example, the follow-up grade of Microeconomics $\mathrm{I}$ is the grade in Microeconomics II.

Panel C shows indicators for students' specialisation choices as well as longer-run outcomes. After students have completed their compulsory first-year courses, they can choose between several follow-up courses. Depending on the respective first-year course, students can take up to seven non-compulsory follow-up courses. Table A1 in the Online Appendix provides an overview of the linkage between first-year and follow-up courses. For any given subject, around $24 \%$ of students choose at least one follow-up course. Similar to the linkage between first-year and follow-up courses, we link first-year courses to majors, whereby it is possible that the same first-year course is linked to multiple follow-up majors. For example, the first-year course Organization and Marketing is linked to two majors-Marketing and Organization. This results in $49 \%$ of students choosing a follow-up major for their respective first-year course. Students can only choose one major; they typically make this decision at the end of the second year. We also create an indicator variable for whether students take any math-intensive elective courses. We classify an elective course as math intensive if its description contains one of the following terms: math, mathematics, mathematical, statistics, statistical or theory focused. In $47 \%$ of cases, students take at least one mathematical elective.

Panel $\mathrm{C}$ further shows that about $69 \%$ of the observed students finish their studies with a degree. To elicit information on study satisfaction and earnings, we conducted an online survey in 2016. The survey had a response rate of $37 \%$. Reassuringly, we find no evidence that rank is related to the response probability. ${ }^{5}$ On average, students have annual entry wages of about EUR 42,500 and retrospectively rate their satisfaction with their overall studies at eight out of ten points.

\subsection{Random Assignment of Students to Teaching Sections}

A key feature of the business school is that, within courses, students are assigned to sections through a conditional random assignment procedure. In a first step, after receiving a list of registered students and available instructors, the scheduler creates time slots and assigns rooms and teachers to these slots. In a second step, students are randomly allocated to the available sections, stratified by nationality. Teachers and students do not interfere with this process. The policy to balance student nationality across sections was implemented in 2011 to avoid having all-German or all-Dutch sections. Some bachelor courses are also stratified by exchange-student status to avoid that, by chance, too many exchange students are allocated to one section. In about $5 \%$ of sections, schedulers must manually adjust the allocation to solve scheduling conflicts that arise if, by chance, a student is scheduled to attend sections in two parallel courses at the same time. To account for this conditioning of the random assignment, we include parallel course fixed effects throughout the paper. In practice, however, these fixed effects have virtually no impact on our results.

The assignment of students to sections is binding. Switching from the assigned section to another is allowed only for medical reasons or when the student is a top athlete and must attend sports practice. To be admitted to the exam, they must not have missed more than three meetings.

\footnotetext{
5 Online Appendix Table A2 displays results from regressions of a survey response indicator on rank, absolute GPA and individual characteristics, resembling our main specification in (1). The estimated coefficient of rank is close to zero and insignificant, which means that our results are not driven by selective survey responses.
}

(C) 2021 Royal Economic Society. 
Instructors keep a record of attendance. The attendance data are not centrally stored and thus are not available to us.

\subsection{External Validity}

We recognise that our data come from only one institution and that students at this business school may not be representative of the higher education population in other countries. However, in contrast to other settings studied in the related literature, e.g., the US Air Force Academy (Carrell et al., 2013), Dartmouth College (Sacerdote, 2001) or Bocconi University (De Giorgi et al., 2010), the school we study is a non-selective institution with substantial diversity in terms of nationalities and socio-economic backgrounds (Feld and Zölitz, 2017). To assess the external validity, it is also noteworthy that the small-group teaching approach used at the institution is quite common in many other environments. Feld et al. (2020) conducted a survey and showed that $63 \%$ of OECD institutions use small-group teaching with class sizes similar to those in our sample. We are therefore not particularly concerned that the rank effects we document in this paper are idiosyncratic to the setting we study.

\section{The Ordinal Achievement Rank}

Our regressor of interest is a student's ordinal rank among her section peers. We compute this rank based on the pre-determined achievement as measured by her GPA of all grades. The GPA is determined before the student is randomly assigned to a section. The rank represents the percentile of a student in the GPA distribution among all students in a section. To construct the percentile rank in a section with $N$ students, we first rank students in absolute terms, assigning rank $N$ to the student with the highest and rank 1 to the student with the lowest GPA in the section. If two or more students have the same GPA, they are assigned the same rank. Because teaching sections differ in size, we convert the absolute rank to a percentile rank that is bounded between 0 (lowest GPA in section) and 1 (highest GPA in section), which ensures that our results are not driven by variation in section size. We compute the percentile rank based on the formula

$$
r=\frac{\text { absolute rank }-1}{N-1} .
$$

For easier interpretability, we standardise the ordinal rank variable to mean zero and an SD of one. ${ }^{6}$ While the percentile rank is not explicitly communicated, students can infer their rank through the intensive student-to-student interaction in the sections. In particular, students may become aware of their rank after the grades from the previous term are released, which often triggers intense discussions among students. For the causal interpretation of our estimates, it is not necessary that students have perfect knowledge of their rank. Students' having imperfect knowledge of their rank is equivalent to measurement error in the rank variable, which may attenuate our estimates and work against finding an effect.

Panel D of Table 1 describes the rank variable. On average, a rank is constructed based on sections with 12.6 students. The percentile rank is bound between 0 and 1 and uniformly distributed with a mean of 0.49 .

\footnotetext{
${ }^{6}$ For the standardisation, we use the SD of the residuals of the rank after conditioning on section fixed effects, which reflects the variation underlying the quasi-experiment.
} 
(a) Different ranks with similar absolute ability and constant section mean

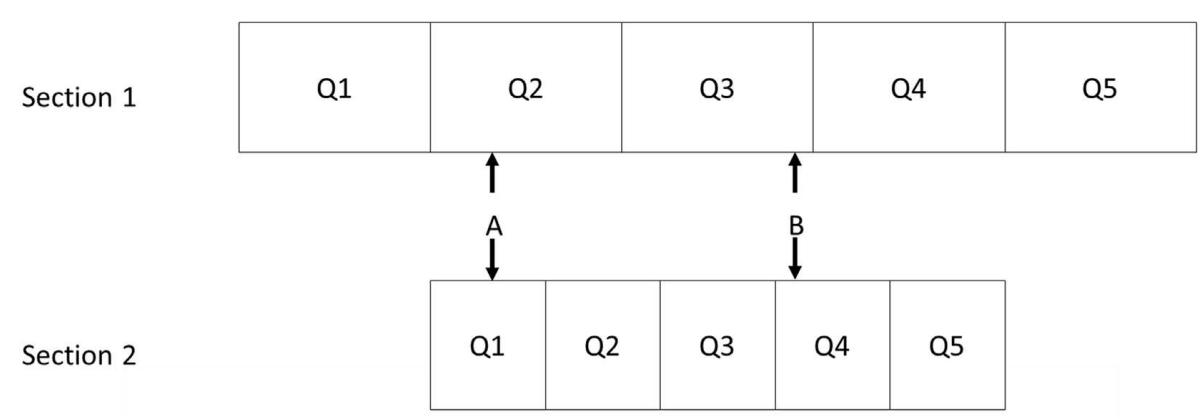

(b) Example sections
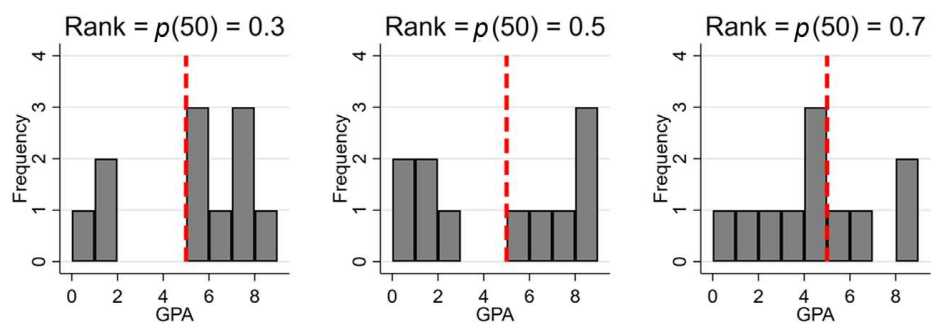

Fig. 1. Variation in Rank.

Notes: This figure illustrates the sources of variation used in the identification of the rank effect. Panel (a) shows how percentile ranks of students A and B would differ if they were assigned to sections 1 and 2 . Both sections only differ in the variance but not in the mean of the section's achievement distribution. With unchanged ability, student A would receive a higher rank in section 1 than in section 2. Student B would receive a lower rank in section 1 than in section 2. Panel (b) displays three example sections. All three sections are of similar mean ability (between the 45th and 55th percentile among all sections in the sample). Dependent on the section's exact shape of the achievement distribution, a student of median achievement may end up with different ranks between the 30th and 70th percentile.

\subsection{Variation in the Ordinal Rank}

For a given GPA, the assignment of students to teaching sections induces considerable variation in their rank, which is illustrated in Figure 1. Panel (a) illustrates the identifying variation similar to Elsner and Isphording (2017) and Murphy and Weinhardt (2020). Panel (a) shows two sections that have the same average achievement but differ in their spread of the achievement distribution. The difference in the variance of achievement results in different percentile ranks for students A and B depending on the section to which they are assigned. Panel (b) shows three exemplary sections in our data. While the sections have a similar average peer achievement, a student with median achievement in the population would be assigned to substantially different ranks. In this example, the rank varies between the 30th and 70th percentile. Thus, panels (a) and (b) highlight how ranks can differ while own and average peer achievement are held constant. A given GPA leads to significant variation in rank because the distributions differ in their variance, skewness, kurtosis and, more broadly, the overall shape. This fact will later enable us to identify the effect of rank conditional on section fixed effects. 
(a)

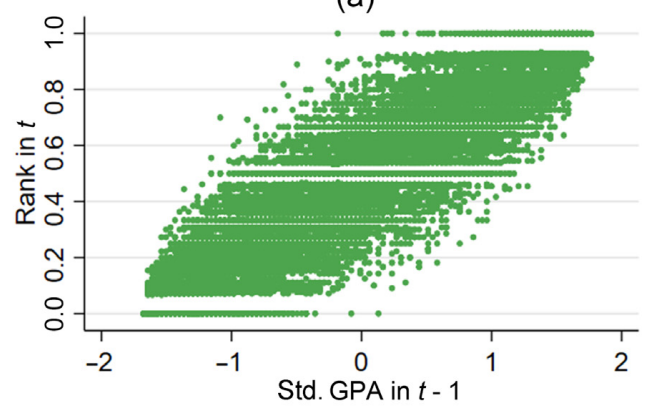

(c)

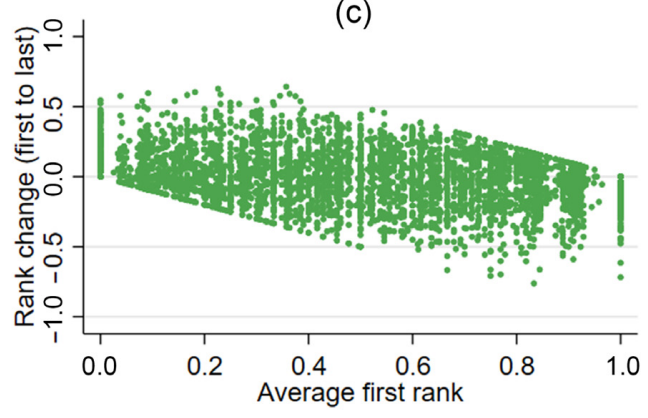

(b)

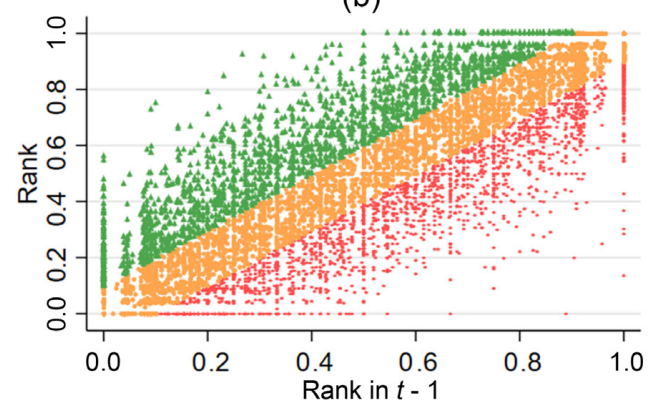

(d)

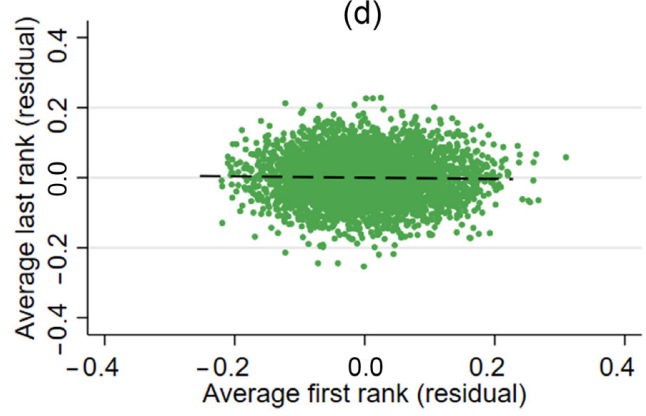

Fig. 2. Dynamic Variation in Rank.

Notes: This figure illustrates the variation in ordinal ranks within and across teaching periods. Panel (a) displays the variation in rank in period $t$ for a given GPA measured in $t-1$ after controlling for section fixed effects. Panel (b) displays variation in rank in a given section in $t$ compared to a student's average rank in $t-1$. The different colours mark changes in ranks by quartile. Green symbols indicate strong upward changes (top quarter of the distribution of rank changes), orange symbols indicate neutral ranks (second and third quartiles) and red symbols indicate strong downward changes (bottom quartile). Panel (c) shows how these upward and downward changes lead to a mechanical convergence between average ranks in the first and last periods. Students who are initially assigned a low rank more likely experience upward rank changes, and vice versa. Panel (d) shows that after conditioning on absolute GPA in the first and last periods, this mechanical correlation vanishes entirely.

Figure 2 displays variation in ranks conditional on achievement, both in the cross section and over time. Panel (a) displays the overall variation in rank in period $t$ for a given GPA measured in $t-1$, after conditioning on section fixed effects. The variation in ranks is largest in the centre of the distribution and lowest in the tails. A student with a median GPA in the overall population may end up with any rank between first and last in a given section. In the tails of the distribution, GPA determines rank almost perfectly because the highest GPA in the overall population always leads to the highest section rank, and likewise, the lowest GPA always results in the lowest section rank.

Panel (b) displays changes in a student's rank in $t$ compared to her average rank in $t-1$. The colours indicate strong positive (green), strong negative (red) as well as little to no changes in rank (orange). ${ }^{7}$ Panel (b) points to substantial dynamics in students' ranks; due to the repeated

\footnotetext{
7 Underlying this classification is the change in rank between two periods, measured by the difference between a student's current rank in a given section and her average rank in the previous section, $\Delta r_{i s c t}=r_{i s c t}-\bar{r}_{i s c, t-1}$. We
} 
random assignment, the same student can experience strong decreases as well as increases in her rank. Panel (c) shows how the upward and downward changes in rank mechanically lead to a convergence between average ranks in the first and last periods. Because of the repeated random assignment, students who are initially assigned a low rank are more likely to experience upward changes and vice versa. Panel (d) highlights the importance of conditioning on absolute GPA, which breaks the mechanical correlation between earlier and later ranks shown in panel (c).

\section{Empirical Strategy}

\subsection{Empirical Model}

Our empirical strategy exploits the random assignment of students into sections within courses, which induces idiosyncratic variation in the ordinal rank for a given GPA level. The same student may have a high rank in one section but a low rank in another, which is purely due to the random assignment of students to sections. Aside from the random assignment-which is unique to our setting - this strategy follows the analysis of rank effects by Murphy and Weinhardt (2020).

In the empirical analysis, we estimate the effect of a student's ordinal rank in first-year sections on contemporaneous performance and longer-run outcomes. Regressions are based on the equation

$$
y_{i s c t}=\beta r_{i s c t}+f\left(\mathrm{gpa}_{i, t-1}\right)+\boldsymbol{X}_{i}^{\prime} \gamma+\boldsymbol{\delta}_{s c t}+\varepsilon_{i s c t} .
$$

The dependent variable $y_{i s c t}$ is the outcome of student $i$ in teaching period $t$, who attends course $c$ and, within this course, has been randomly assigned to section $s .{ }^{8}$ Therefore, each section is nested in a unique period-course combination. We regress this outcome on the student's percentile rank within section $s, r_{i s c t} \in[0,1]$, which is a function of the student's own pre-determined GPA measured at the end of period $t-1$ as well as the distribution of the student's own pre-determined GPA in section $s$. To isolate the effect of rank for a given level of achievement, we control for a function of pre-determined GPA. In our preferred specification, we include a third-order polynomial, although we later show robustness checks with polynomials of different orders as well as more flexible controls based on decile dummies. The vector $\boldsymbol{X}_{i}$ controls for pre-determined individual characteristics, namely age, gender and indicators for nationality (Dutch, German or other). In addition, we follow Murphy and Weinhardt (2020) and Elsner and Isphording (2017) by conditioning on section fixed effects $\boldsymbol{\delta}_{s c t}$. These fixed effects are central to our identification strategy, as they absorb all average differences in observable and unobservable characteristics between sections. Importantly, this includes any peer group characteristic that is the same for all students within a section, for example, the mean ability or the variance in ability.

The error term $\varepsilon_{i s c t}$ captures all determinants of the outcome that are not captured by other regressors. Given the likely cross-sectional dependence of error terms, it is necessary to adjust the SEs for clustering. Two dimensions of dependence are particularly important. First, we observe each student multiple times, and the error terms of the same student are likely correlated. Second,

classify changes in the top quartile of the distribution of $\Delta r_{i s c t}$ as strong increases and changes in the bottom quartile as strong decreases. The third category-denoting little or no change-includes all rank changes in the second and third quartiles.

${ }^{8}$ We run all our main specifications at the student-course level, as this replicates the hypothetical experiment wherein students are randomly assigned to sections within courses. For comparison, we also perform an analysis at the student level, whereby the regressor is a student's average rank. The results, which are available upon request, confirm our main results at the student-section level. 
students are assigned to sections within the same course, which means that the error terms may have a course-specific component and therefore may be correlated within courses. We account for these correlations by adjusting the SEs for two-way clustering at the student and course levels. ${ }^{9}$ In Online Appendix Table A3, we also present SEs with one-way clustering at various levels, which are consistently smaller than the two-way clustered SEs.

\subsection{Identification}

\subsubsection{Identifying variation}

Our coefficient of interest, $\beta$, measures the marginal impact of a higher ordinal rank on the outcome, holding constant the GPA level and controlling for section fixed effects. While it is intuitive that random assignment of students induces idiosyncratic variation in the ordinal rank, critical readers may wonder where the identifying variation comes from when we condition on section fixed effects. The coefficient $\beta$ can be identified on top of section fixed effects because rank is individually assigned within sections. By conditioning on section fixed effects, we perform a within-transformation that subtracts the section mean from each variable. While this transformation centres the (residual) ability distribution of each section at the same mean, it does not change the shape of the ability distribution. Therefore, despite controlling for section fixed effects, the ordinal ranking is preserved and $\beta$ is identified from differences across sections in the variance, skewness, kurtosis and higher moments of the ability distribution. Intuitively, we identify $\beta$ by comparing students with the same GPA across all sections in the sample after controlling for mean differences across sections. Online Appendix Table A4 quantifies the identifying variation in the most important variables. Even after controlling for individual GPA and section fixed effects, a considerable degree of variation remains.

\subsubsection{Identifying assumption}

For $\beta$ to be causally identified, the rank has to be as good as randomly assigned, such that the following assumption of strict exogeneity holds:

$$
\operatorname{cov}\left(\varepsilon_{i s c t}, r_{i s c t} \mid f\left(\mathrm{gpa}_{i, t-1}\right), \boldsymbol{X}_{i}, \boldsymbol{\delta}_{s c t}\right)=0 .
$$

In our setting, the validity of this assumption is plausible for two reasons. First, by conditioning on section fixed effects $\boldsymbol{\delta}_{s c t}$, we eliminate all potential confounders at the peer group level. This is important because we aim to identify the rank effect net of all other mechanisms through which peers affect individual outcomes. For example, the section fixed effects absorb variation in mean GPA across sections, in variance in GPA, in the share of high-ability peers-however high ability is defined - and in the share of female students, share of immigrants, etc. All these variables arguably have a direct effect on the outcome, but these direct effects are eliminated by the fixed effects. Furthermore, the section fixed effects absorb any shock that is common to all students within a section.

Second, the random assignment of students to sections ensures that a student's rank, conditional on GPA, is uncorrelated with the student's observable and unobservable characteristics. In particular, the random assignment prevents students from strategically choosing sections to achieve a high rank, which is a potential source of bias in studies based on non-random assignment.

\footnotetext{
${ }^{9}$ When referring to the course level, we implicitly refer to unique cohort-term-course combinations; for example, the grades in microeconomics in the second term of the starting cohort in 2008.
} 
Table 2. Randomisation Check—Dependent Variable: Individual-Level Characteristics.

\begin{tabular}{lcc}
\hline \hline & $(1)$ & $(2)$ \\
& Rank & Rank \\
\hline Female & -0.0075 & 0.0237 \\
& $(0.031)$ & $(0.040)$ \\
Dutch & 0.0047 & 0.0287 \\
& $(0.024)$ & $(0.025)$ \\
German & 0.0211 & -0.0576 \\
& $(0.027)$ & $(0.041)$ \\
Exchange student & 0.0011 & 0.0009 \\
Age & $(0.001)$ & $(0.002)$ \\
& 0.1532 & 0.1295 \\
Parallel course FEs & $(0.094)$ & $(0.131)$ \\
Section FEs & Yes & Yes \\
\hline \hline
\end{tabular}

Notes: Each cell in the table represents the coefficient from a separate regression of the respective student characteristics displayed on the left on rank and the fixed effects displayed at the bottom. All regressions include a third-order polynomial in GPA. Robust SEs, clustered at the student and course levels, are displayed in parentheses. Here $N=23,694$. ${ }^{* * *} p<0.01,{ }^{* *} p<0.05,{ }^{*} p<0.1$.

\subsubsection{Quasi-random assignment of the ordinal rank}

To confirm that our measure of the ordinal rank is as good as randomly assigned, in Table 2 we perform balancing tests in which we regress student characteristics on the ordinal rank, a third-order polynomial in GPA, as well as various sets of fixed effects. None of the coefficients is statistically significant, which is consistent with the random assignment of students to sections and supports the assumption of strict exogeneity of rank conditional on GPA and section fixed effects (FEs).

\subsubsection{Challenges to identification}

Despite the random assignment, two challenges to identification remain. One is functional form, as strict exogeneity only holds if the specification error-a component of $\varepsilon_{i s c t}$-is uncorrelated with a student's rank. A second challenge is measurement error in the ability variable, which may lead to spurious rank effects. We address both challenges in robustness checks in the next section.

\section{Main Results}

\subsection{Ordinal Rank and Student Performance}

We first estimate the effect of rank on contemporaneous performance in the first year. Table 3 displays the estimated effects of the ordinal rank on four measures of performance. This and the following tables report coefficients from separate regressions of the dependent variables shown in the column headers on the ordinal rank, adjusted for a third-order polynomial in pre-determined GPA, individual characteristics and the fixed effects listed at the bottom. Each coefficient represents the marginal effect of an increase in a student's ordinal rank within a section, holding constant individual achievement and mean peer achievement as well as all other factors that are constant across all members of a section. Because of the standardisation, the coefficients (C) 2021 Royal Economic Society. 
Table 3. The Impact of Rank on Performance.

\begin{tabular}{lcccc}
\hline \hline & $(1)$ & $(2)$ & $(3)$ & $(4)$ \\
& Course dropout & Passed course & Std. grade & Std. follow-up grade \\
\hline Std. rank & $-0.0227^{* * *}$ & $0.0321^{* * *}$ & $0.0666^{* * *}$ & $0.0403^{* * *}$ \\
& $(0.003)$ & $(0.004)$ & $(0.007)$ & $(0.010)$ \\
Observations & 23,694 & 23,694 & 21,976 & 9,470 \\
$R^{2}$ & 0.222 & 0.435 & 0.602 & 0.477 \\
Mean dependent variable & 0.072 & 0.704 & -0.002 & -0.005 \\
Section FEs & Yes & Yes & Yes & Yes \\
Parallel course FEs & Yes & Yes & Yes & Yes \\
\hline \hline
\end{tabular}

Notes: Each cell reports the point estimate from a separate OLS regression of the performance measure listed at the top on the standardised section rank. All regressions control for gender, age, nationality and a third-order polynomial in GPA. Robust SEs, clustered at the student and course levels, are reported in parentheses. ${ }^{* * *} p<0.01$, ${ }^{* *} p<0.05,{ }^{*} p<0.1$.

are to be interpreted as the effect of a one SD increase in the ordinal rank-an increase of about 12 percentiles, or about 1.4 rank position in a section of 12 students.

Column (1) shows that a higher ordinal rank significantly reduces the likelihood of dropping out of the course. A one SD increase in the ordinal rank reduces dropout risk by 2.3 percentage points. Similarly, an increase in the rank by one SD increases the likelihood of passing the course by 3.2 percentage points, which is equivalent to about $5 \%$ of the mean (column (2)). Columns (3) and (4) reveal economically and statistically significant effects of the ordinal rank on performance. A one SD increase in the ordinal rank increases the grade at the end of the course by $6.7 \%$ of an SD and the standardised grade in a follow-up course by $4 \%$ of an SD. The effect of rank on standardised grades is similar in magnitude to the effect found by Murphy and Weinhardt (2020) for secondary school children in England. Moreover, the effect of rank appears to be more important than spillovers of higher average peer ability or an instructor with a higher value added. In the same setting, Feld and Zölitz (2017) estimated that a one SD increase in the average peer GPA causes an increase of $1.26 \%$ of an SD in student grades. An instructor with a one SD higher value added increases students' grades by $2 \%$ of an SD (Feld et al., 2020).

Despite differences in the setting and the extent of peer exposure, our main finding - an increase in performance of around $7 \%$ for a one SD-is in the same ballpark as recent results by Murphy and Weinhardt (2020), who studied rank effects in British primary and secondary schools. In their setting, a one SD increase in rank based on standardised test scores in primary school increases test scores at ages $14-16$ by about $8 \%$ of an SD. Denning et al. (2020) found similar-sized effects for students in that same age group in Texas. It is perhaps surprising that the short-term exposure to a peer group at a Dutch business school leads to similar rank effects as the year-long exposure to school peers in Britain or Texas. One explanation for the similarity in effect sizes may lie in the uncertainty about one's own ability, which is particularly high at the beginning of college (Arcidiacono et al., 2016). During this period, the signal contained in one's ordinal rank may play a particularly important role. Results of Bertoni and Nisticò (2019) suggest that the effects of rank at the beginning of college can be even larger if peer groups stay together for a longer period. They used data from an experiment at the University of Amsterdam, where peer groups stay together for the entire first year, and found a much larger rank effect: a one SD increase in rank increases math test scores by $25 \%$ of an SD. 
Our second finding - that a high rank in a given subject increases the probability of majoring in that subject-is also in line with the earlier literature. Although the effect sizes are difficult to compare across settings, both Murphy and Weinhardt (2020) and Denning et al. (2020) showed that changes in the ordinal rank early in a student's career affect later specialisation choices.

Given that a rank effect is a specific type of peer effect, our results can be compared to those in the literature identifying 'classical' peer spillovers in similar settings. Feld and Zölitz (2017) found positive but small peer spillovers in the same setting: having peers of a one SD higher ability improves own performance by $1.26 \%$ of an SD. This suggests that a person's ordinal rank within a peer group is more important for performance and choices than the average peer ability. However, given our research design, it is not possible to separately identify peer and rank effects, as the average peer quality and a person's rank are the result of the same random assignment. Both are mechanically correlated, which is why one cannot estimate separate causal effects in the same regression as well as determine which effect is stronger. ${ }^{10}$ Disentangling both effects is possible in a regression discontinuity design, as demonstrated by Ribas et al. (2020). The authors exploited the fact that the change in ordinal rank at an admission cutoff to an advanced study programme is constant across years-a student is either the highest ranked in the weak group or the lowest rank in the strong group-whereas the difference in average peer ability varies from year to year. They found that negative performance effects due to a lower rank outweigh the positive spillovers from having better peers. A comparison of the substantial rank effects we find in this paper with the moderate peer effects by Feld and Zölitz (2017) points in a similar direction.

The binned scatter plot in Figure 3 sheds further light on the functional relationship between within-section rank and performance. The regression line is equivalent to the coefficient in column (3) of Table 3. While the relationship is not fully linear-there appears to be a plateau in the middle of the distribution of ranks - the dots are close to the regression line, ruling out strong non-linearities. This relationship is closer to the linear one found for secondary school students (Murphy and Weinhardt, 2020) than the non-linear relationships found in experiments that emphasise the importance of being ranked first or last (Kuziemko et al., 2014; Gill et al., 2019).

\subsection{Dynamic Effects}

After documenting a strong positive effect of rank on performance, we explore how students respond to changes in their rank. If the ordinal rank is a signal for ability, changes in the rank may induce students to update their beliefs about their own ability and adjust their effort.

We begin by testing to what extent earlier ranks are more-or less-important than later ranks. On the one hand, uncertainty about one's own ability might be larger at the early stages, in which case an early rank would have a larger effect. On the other hand, a student might first have to understand the new college setting to adequately process information provided by the rank. In that case, we would expect later ranks to have a larger effect. In Table 4, we interact the rank with an indicator for the first period in which we observe a student's rank. ${ }^{11}$ The results suggest

\footnotetext{
${ }^{10}$ Note that this does not imply that peer and rank effects cannot be identified at all. Most papers identify the effect of the ordinal rank by controlling for peer quality through peer group fixed effects. Likewise, as pointed out by Bertoni and Nisticò (2019), studies that seek to estimate the causal effect of average peer quality on individual outcomes should control for a person's ordinal rank, as they would otherwise obtain biased estimates.

${ }^{11}$ Because we construct the rank based on pre-determined GPA, the first period in which we observe the rank is the second teaching period.
}

(C) 2021 Royal Economic Society. 


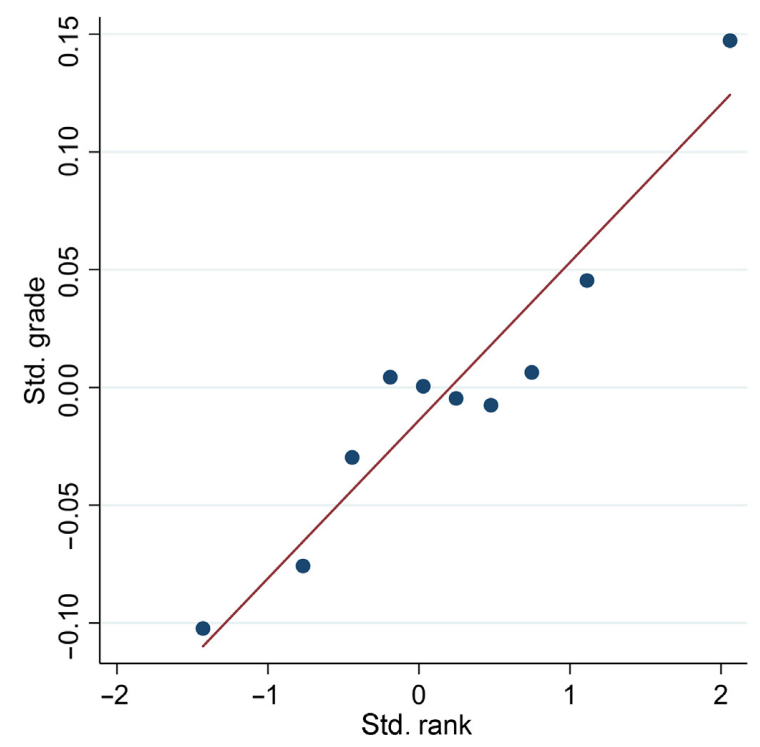

Fig. 3. Non-Linear Effect of Rank on Student Performance.

Notes: This graph displays the relationship between the standardised rank within a section and the standardised grade in a given course. We condition on the same control variables and fixed effects as in Table 3 .

Table 4. Early versus Later Ranks.

\begin{tabular}{lcccc}
\hline \hline & $(1)$ & $(2)$ & $(3)$ & $(4)$ \\
& Course dropout & Passed course & Std. grade & Std. follow-up grade \\
\hline Std. rank $\times$ first period & $0.0086^{* *}$ & -0.0023 & $-0.0331^{* *}$ & $-0.0507^{* * *}$ \\
Std. rank & $(0.004)$ & $(0.006)$ & $(0.015)$ & $(0.016)$ \\
& $-0.0247^{* * *}$ & $0.0326^{* * *}$ & $0.0748^{* * *}$ & $0.0485^{* * *}$ \\
Observations & $(0.003)$ & $(0.004)$ & $(0.009)$ & $(0.011)$ \\
$R^{2}$ & 23,694 & 23,694 & 21,976 & 9,470 \\
Mean dependent variable & 0.223 & 0.435 & 0.604 & 0.479 \\
Parallel course FEs & 0.0723 & 0.7038 & -0.0017 & -0.0045 \\
Section FEs & Yes & Yes & Yes & Yes \\
\hline \hline
\end{tabular}

Notes: This table displays regressions at the student-section level of the outcomes listed above on the standardised rank and its interaction with an indicator for the first period in which students observe their GPA, that is, the second term. All regressions control for gender, age, nationality, a third-order polynomial in GPA as well as the fixed effects listed at the bottom. Robust SEs, clustered at the student and course levels, are displayed in parentheses. ${ }^{* * *} p<0.01$, ${ }^{* *} p<0.05,{ }^{*} p<0.1$.

that the effect of rank is about half the size in the first observed period compared to later periods. The effect on follow-up grades materialises in later periods only.

In a further step, we analyse whether students respond to large changes in their rank and whether the responses differ between positive and negative changes. We base the analysis on the difference between student $i$ 's rank in section $s$ in period $t$ and the student's average rank in both sections in the previous period $t-1, \Delta r_{i s c t}=r_{i s c t}-\bar{r}_{i s c, t-1} \cdot{ }^{12}$ From the distribution of rank

\footnotetext{
12 Because of the lag term in $\Delta r_{i s c t}$, we can only analyse rank changes in the third and fourth teaching periods of the first year. For each student in the sample, we observe four rank changes: two in period 3 relative to period 2 and two in period 4 relative to period 3 . This explains the lower number of observations in Table 5.
}

(C) 2021 Royal Economic Society. 
Table 5. Rank Changes.

\begin{tabular}{lcccc}
\hline \hline & $(1)$ & $(2)$ & $(3)$ & $(4)$ \\
& Course dropout & Passed course & Std. grade & Std. follow-up grade \\
\hline Rank up & -0.0011 & 0.0126 & $0.0559^{* * *}$ & $0.0653^{* *}$ \\
& $(0.006)$ & $(0.008)$ & $(0.019)$ & $(0.025)$ \\
Rank down & 0.0081 & -0.0151 & -0.0320 & 0.0347 \\
& $(0.007)$ & $(0.011)$ & $(0.022)$ & $(0.030)$ \\
Observations & 13,839 & 13,839 & 12,762 & 6,743 \\
$R^{2}$ & 0.257 & 0.455 & 0.602 & 0.476 \\
Mean dependent variable & 0.078 & 0.710 & 0.055 & -0.025 \\
Parallel course FEs & Yes & Yes & Yes & Yes \\
Section FEs & Yes & Yes & Yes & Yes \\
\hline \hline
\end{tabular}

Notes: All models include third-order polynomials of current and past GPA, controls for gender, age and nationality, and the fixed effects listed at the bottom. Rank up is an indicator that equals one if a student's change in rank relative to the previous term is in the top quartile of all rank changes. Rank down is an indicator for the bottom quartile of all rank changes. The reference category includes rank changes in the second and third quartiles. Robust SEs, clustered at the student and course levels, are displayed in parentheses. ${ }^{* * *} p<0.01,{ }^{* *} p<0.05,{ }^{*} p<0.1$.

changes $\Delta r_{i s c t}$, we construct indicators for strong increases and strong decreases. We classify a change as a strong increase if it lies in the top quartile of the distribution of changes and a strong decrease if it lies in the bottom quartile.

Table 5 presents the results of regressions of performance outcomes on the indicators for strong increases or decreases in rank. The omitted category is rank changes in the second or third quartile of the distribution of $\Delta r_{i s c t}$, which represent no or small changes in the ordinal rank. The controls are identical to those in our main specification in Table 3. The effects on dropout risk and course passing, shown in columns (1) and (2), have the expected signs but are small and statistically insignificant. Columns (3) and (4), in contrast, reveal strong asymmetric responses of performance to changes in rank. A strong increase in rank raises the grade in a given course as well as in a follow-up course by around 6\% of an SD. The effect of a strong decrease in rank is smaller-around $3 \%$ of an SD—and statistically insignificant.

We further explore whether positive and negative signals have a cumulative effect, that is, whether students respond differentially to receiving multiple positive or negative signals. For this purpose, we restrict the estimation sample to the fourth teaching period of the first year-the last period in which we observe a student's rank-such that, for each student, we observe four rank changes. ${ }^{13}$ We then regress the standardised grade on indicators for the cumulative number of positive and negative signals a student receives. The omitted category is students whose rank remained stable in all sections in periods 3 and 4 . The controls are the same as in Table 3.

The results in Figure 4 point to an effect of accumulated positive and negative signals. Every additional positive signal leads to an increase in performance. This relationship holds for up to three positive signals, whereas a fourth positive signal has no significant additional effect on performance. Similarly, every additional negative signal has a negative effect, although the effect is less pronounced than for positive signals. Given the confidence intervals, we cannot exclude

13 The cumulative number of negative and positive signals that a student can receive in the first year is bounded between -4 and +4 . In period 2, the first period in which a student's rank can be computed, a comparison to a pre-period is not possible. In both periods 3 and 4, the student takes two courses each and therefore is assigned to two sections. In each section, we observe a change in rank relative to the average pre-period rank. Restricting the sample to the fourth teaching period only ensures that we observe the same number of signals for all student-section combinations. We obtain similar results when we include student-section combinations in the third period. 


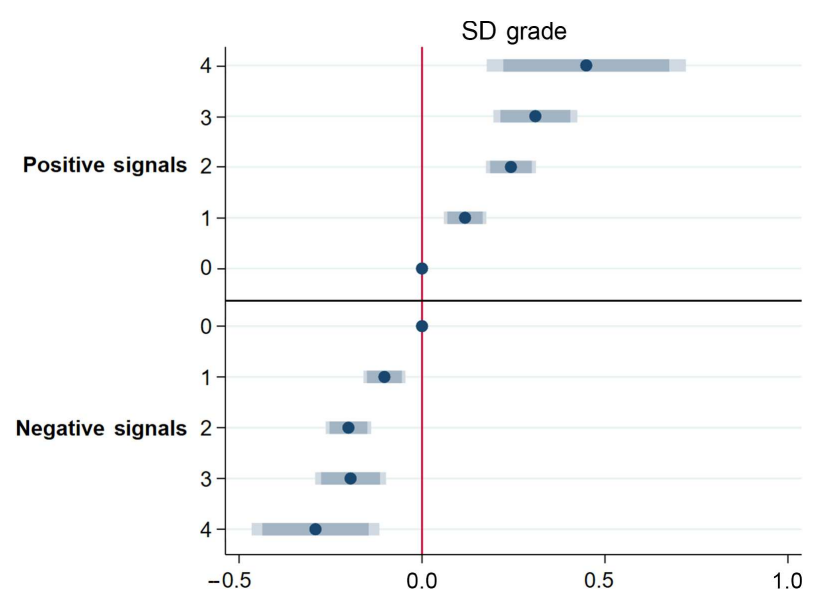

Fig. 4. Impact of Accumulated Positive and Negative Signals.

Notes: The graph displays the coefficients and confidence intervals from a regression of standardised grades on dummy variables for the number of positive and negative rank changes in the first year. Each observation is a student-section combination in the fourth teaching period. The regression includes section fixed effects and a third-order polynomial in first-term GPA. Rank changes are defined the same way as in Table 5. The number of signals refers to the number of positive or negative rank changes a student has experienced in teaching terms 3 and 4 . Horizontal bars indicate $95 \%$ and $99 \%$ confidence intervals, respectively, based on SEs clustered at the student and course levels.

that the additional effects beyond the first negative signal are zero. ${ }^{14}$ Overall, Figure 4 confirms the asymmetric effects found in Table 5. Students respond more strongly to positive than to negative signals.

\subsection{Robustness Checks}

\subsubsection{Functional form}

The causal identification of the rank effect crucially depends on correctly specifying the functional form of the relationship between absolute GPA and the outcome. To ensure that the effect of rank is not confounded by the direct effect of absolute achievement on performance and choices, it is vital to correctly specify the effect of absolute achievement. In Online Appendix Table A5, we assess the robustness of our results to different parametric and non-parametric controls for absolute GPA. We parametrically control for GPA with polynomials up to the fourth order and show alternative specifications in which we semi-parametrically control for GPA with decile dummies. The estimated effects prove robust to the different specifications, which suggests that our results are not driven by specification errors.

\subsubsection{Multiplicative measurement error}

As pointed out by Murphy and Weinhardt (2020), non-standard multiplicative measurement error in the normally distributed ability measure may lead to spurious rank effects. This problem can be circumvented through a transformation of the ability measure into a uniform distribution and

\footnotetext{
${ }^{14}$ Given that the number of signals results from the sampling distribution of ranks, large numbers of positive or negative rank changes are not as likely to occur as small numbers. The share of observations with four positive signals or four negative signals is below $1 \%$ for each. The share without significant changes in rank is $44 \%$.
} 
the construction of the ordinal rank based on the transformed measure. Online Appendix Table A6 displays our main regression results based on the transformed achievement measure and the same parametric and semi-parametric controls for GPA as in Online Appendix Table A5. The results are similar to our main results, both in terms of size and statistical significance.

\subsubsection{Inference}

We adjust the SEs for two-way clustering at the student and course levels because (i) we observe each student multiple times in the sample, and hence their error terms may not be independent, and (ii) students are randomised into sections within the same course. Because grading occurs at the course level, the error terms within a course may be correlated. In Online Appendix Table A3, we show that our adjustment is conservative in the sense that it produces larger SEs compared to one-way clustering at the section, course or student levels.

\section{Additional Results}

\subsection{Effect of Rank on Specialisation Choices and Long-Run Outcomes}

Besides having a strong positive effect on contemporaneous performance, a student's rank may also affect longer-run outcomes by, for example, changing beliefs about one's success in a given specialisation. To examine longer-term effects, we focus on specialisation choices and longrun outcomes such as study satisfaction or earnings. Specialisation choices within business and economics are presumably less consequential than the decision to go to college or the choice of whether to study art history or engineering. Nonetheless, the literature has shown that major choices lead to earning differences, if, for example, choosing a major affects the subsequent choice of occupation (Arcidiacono, 2004) or if the major choice reflects an investment in jobspecific human capital (Wiswall and Zafar, 2015). In our setting, shortly after graduation, finance majors earn EUR 57,000, whereas marketing majors earn EUR 43,000 per year.

One channel through which a student's rank may affect major choices is changing beliefs about the comparative advantages of some fields versus others. If, for example, a student is highly ranked in quantitative methods but ranks low in introductory microeconomics, she might believe that she has a comparative advantage in quantitative over theoretical content. The effect on beliefs may sway students in their later major choices, above and beyond the direct effect of rank on performance.

To estimate the impact of rank on specialisation choices, we construct four indicators: (i) a binary indicator for whether a student chooses any follow-up course to the respective first-year course, (ii) the number of follow-up courses a student chooses, (iii) an indicator for whether a student chooses any elective with a high math intensity and (iv) an indicator for whether a student graduates in a related major. As long-run outcomes, we use (i) an indicator for whether a student graduated within four years, (ii) a retrospective measure of study satisfaction on a scale from 1 to 10 and (iii) log earnings.

When estimating the effect of the ordinal rank on these outcomes, the treatment varies at the student-course level whereas the outcome only varies at the student level. This means that if we observe a student in six courses, the same outcome is observed six times. In this set-up, the coefficients represent the effect of a higher rank in one course on the outcome.

Columns (1)-(4) of Table 6 show that the ordinal rank significantly affects specialisation choices. A one SD increase in rank increases the probability of taking a follow-up course in (C) 2021 Royal Economic Society. 
Table 6. The Impact of Rank on Specialisation Choice and on Longer-Run Outcomes.

\begin{tabular}{|c|c|c|c|c|c|c|c|}
\hline & $\begin{array}{l}\text { Taking follow-up } \\
\text { course }\end{array}$ & $\begin{array}{l}\text { Number of } \\
\text { follow-up courses }\end{array}$ & $\begin{array}{l}\text { (3) } \\
\text { Graduating in } \\
\text { related subject } \\
\text { major }\end{array}$ & $\begin{array}{l}\text { (4) } \\
\text { Taking math } \\
\text { electives }\end{array}$ & Graduation & $\begin{array}{c}\text { Study } \\
\text { satisfaction }\end{array}$ & Log earnings \\
\hline Std. rank & $\begin{array}{l}0.0123^{* * *} \\
(0.003)\end{array}$ & $\begin{array}{l}0.0190^{* * *} \\
(0.007)\end{array}$ & $\begin{array}{l}0.0223^{* * *} \\
(0.005)\end{array}$ & $\begin{array}{l}0.0311^{* * *} \\
(0.005)\end{array}$ & $\begin{array}{l}0.0512^{* * *} \\
(0.006)\end{array}$ & $\begin{array}{c}0.0042 \\
(0.024)\end{array}$ & $\begin{array}{c}-0.0124 \\
(0.025)\end{array}$ \\
\hline Observations & 23,790 & 23,790 & 23,790 & 23,790 & 13,729 & 8,205 & 6,251 \\
\hline$R^{2}$ & 0.339 & 0.347 & 0.442 & 0.396 & 0.387 & 0.212 & 0.319 \\
\hline $\begin{array}{l}\text { Mean dependent } \\
\text { variable }\end{array}$ & 0.242 & 0.365 & 0.488 & 0.474 & 0.695 & 8.074 & 10.235 \\
\hline Parallel course FEs & Yes & Yes & Yes & Yes & Yes & Yes & Yes \\
\hline Section FEs & Yes & Yes & Yes & Yes & Yes & Yes & Yes \\
\hline
\end{tabular}

Notes: Each cell reports the point estimate from a separate OLS regression of the outcome listed at the top on the standardised section rank. The outcome varies at the student-level whereas most regressors vary at the student-section level. All regressions control for gender, age, nationality, a third-order polynomial in GPA and the fixed effects listed at the bottom. The number of observations in column (5) is lower than in the previous columns as we limit the estimation sample to students who could have graduated over the time span that we observe them. The numbers of observations in columns (6) and (7) are lower than in the previous column due to non-response to the graduate survey. Robust SEs, clustered at the student and course levels, are reported in parentheses. ${ }^{* * *} p<0.01,{ }^{* *} p<0.05,{ }^{*} p<0.1$.

a related subject by 1.2 percentage points and increases the number of follow-up courses by 1.9 percentage points. Similarly, in column (3), we find a strong effect on the probability of graduating in a related major. An increase in rank by one SD increases this probability by 2.2 percentage points. Column (4) shows a large and statistically significant effect on the probability of choosing electives with a high math intensity. For a one SD increase in rank, the choice probability increases by 3.1 percentage points.

The effect of rank on long-run outcomes, shown in columns (5)-(7), is less clear-cut than the effect on choices. While we find a significant positive effect on the probability of graduation, we find neither significant effects on study satisfaction nor earnings. The insignificant effect on earnings should be interpreted with caution, as the earnings data are much noisier than the data on performance and choices. The earnings data are based on a non-random subsample and are self-reported, which means that they are likely subject to measurement error and selective misreporting. However, as shown in Online Appendix Table A2, the probability of responding is unrelated to rank.

\subsection{Gender Differences in Rank Effects}

In Table 7, we explore whether the effect of rank on performance and choices differs by gender. The literature documents a significant gender gap in the willingness to compete (Niederle and Vesterlund, 2007; Andersen et al., 2013; Sutter and Glätzle-Rützler, 2014). Along similar lines, several pieces of evidence show that male students are more likely than female students to rely on within-classroom comparisons to shape their beliefs about their relative ability (Chevalier et al., 2009; Kuyper et al., 2011; Cooper et al., 2018). If female students indeed dislike competing and male students are more likely to rely on classroom comparisons, one may expect the ordinal rank to be less important to women than to men. This notion is confirmed by Murphy and Weinhardt (2020), who showed that male secondary students are more responsive to their rank compared to female students.

To test for gender differences in students' responses to their ordinal rank, we re-estimate our main specification and interact the rank with an indicator for female. The results in Table 7 point 
Table 7. Gender Differences in the Impact of Rank.

\begin{tabular}{|c|c|c|c|c|}
\hline & $\begin{array}{c}\text { (1) } \\
\text { Course dropout }\end{array}$ & $\begin{array}{c}(2) \\
\text { Passed course }\end{array}$ & $\begin{array}{c}(3) \\
\text { Std. grade }\end{array}$ & $\begin{array}{c}\text { (4) } \\
\text { Std. follow-up grade }\end{array}$ \\
\hline \multicolumn{5}{|l|}{ Panel A: performance } \\
\hline Female $\times$ std. rank & $\begin{array}{l}0.0078^{* * *} \\
(0.002)\end{array}$ & $\begin{array}{c}-0.0005 \\
(0.002)\end{array}$ & $\begin{array}{c}-0.0063 \\
(0.005)\end{array}$ & $\begin{array}{c}-0.0133 \\
(0.008)\end{array}$ \\
\hline Std. rank & $\begin{array}{l}-0.0253^{* * *} \\
(0.003)\end{array}$ & $\begin{array}{l}0.0323^{* * *} \\
(0.004)\end{array}$ & $\begin{array}{l}0.0693^{* * *} \\
(0.007)\end{array}$ & $\begin{array}{l}0.0440^{* * *} \\
(0.010)\end{array}$ \\
\hline Observations & 23,790 & 23,790 & 22,068 & 9,519 \\
\hline$R^{2}$ & 0.222 & 0.435 & 0.602 & 0.476 \\
\hline Mean dependent variable & 0.072 & 0.704 & -0.002 & -0.003 \\
\hline Parallel course FEs & Yes & Yes & Yes & Yes \\
\hline \multirow[t]{2}{*}{ Section FEs } & Yes & Yes & Yes & Yes \\
\hline & $\begin{array}{l}\text { Taking follow-up } \\
\text { course }\end{array}$ & $\begin{array}{c}\text { Number of follow- } \\
\text { up courses }\end{array}$ & $\begin{array}{c}\text { Taking math } \\
\text { electives }\end{array}$ & $\begin{array}{c}\text { Graduating in related } \\
\text { subject major }\end{array}$ \\
\hline \multicolumn{5}{|c|}{ Panel B: specialisation choices } \\
\hline Female $\times$ std. rank & $\begin{array}{l}-0.0061^{* * *} \\
(0.002)\end{array}$ & $\begin{array}{l}-0.0135^{* * *} \\
(0.003)\end{array}$ & $\begin{array}{c}-0.0138^{* * *} \\
(0.004)\end{array}$ & $\begin{array}{c}-0.0070 \\
(0.004)\end{array}$ \\
\hline Std. rank & $\begin{array}{l}0.0144^{* * * *} \\
(0.004)\end{array}$ & $\begin{array}{l}0.0236^{* * *} \\
(0.007)\end{array}$ & $\begin{array}{l}0.0359^{* * *} \\
(0.005)\end{array}$ & $\begin{array}{l}0.0247^{* * *} \\
(0.005)\end{array}$ \\
\hline Observations & 23,790 & 23,790 & 23,790 & 23,790 \\
\hline$R^{2}$ & 0.339 & 0.347 & 0.397 & 0.442 \\
\hline Mean dependent variable & 0.242 & 0.365 & 0.474 & 0.488 \\
\hline Parallel course FEs & Yes & Yes & Yes & Yes \\
\hline Section FEs & Yes & Yes & Yes & Yes \\
\hline
\end{tabular}

Notes: Each cell reports the point estimate from a separate OLS regression of the performance measure listed at the top on the standardised section rank. All regressions control for gender, age, nationality and a third-order polynomial in GPA. Robust SEs, clustered at the student and course levels, are reported in parentheses. ${ }^{* * *} p<0.01$, ${ }^{* *} p<0.05,{ }^{*} p<0.1$.

to significant gender differences. In general, female students show a weaker response than male students. With respect to first-year performance (panel A), the effect of rank on dropout is onethird smaller for female compared to male students. Gender differences in the effect on grades and follow-up grades are statistically insignificant but point in the same direction. For third-year choices (panel B), the differences are more pronounced. The effects on the likelihood of choosing a follow-up course, the number of follow-up courses and on choosing a math-intensive elective are about twice as large for male as for female students. Taken together, these results confirm the higher responsiveness of male students to within-classroom comparisons found in the previous literature.

We analyse a second channel through which gender may interact with ordinal rank, namely, a student's reference group. Rather than comparing themselves to all students in a section, students may compare themselves to peers with similar characteristics, such as gender. To test whether a student's rank within her same-gender group is indeed a better predictor for performance than her overall rank, we construct a student's same-gender rank as the percentile rank among all section peers of the same gender. However, the results in Online Appendix Table A7 indicate that the same-gender rank has no additional effect over and above the overall rank. ${ }^{15}$ We can thus reject a hypothesis that rank comparisons among same-gender peers are more important than comparisons among all peers.

\footnotetext{
15 Note that, using this alternative and a more narrow definition of a peer group, also implies a smaller group size and higher residual variation in ranks, as shown in Table A4. 
Table 8. Mechanisms-Evidence from Student Course Evaluations.

\begin{tabular}{lccc}
\hline \hline & $(1)$ & $(2)$ & $(3)$ \\
& Peer interaction index & Study hours & Teacher evaluation index \\
\hline Std. rank & $-0.0192^{*}$ & 0.0369 & 0.0066 \\
& $(0.011)$ & $(0.108)$ & $(0.011)$ \\
Observations & 7,423 & 6,902 & 7,245 \\
$R^{2}$ & 0.376 & 0.286 & 0.606 \\
Mean dependent variable & -0.041 & 11.925 & -0.055 \\
Parallel course FEs & Yes & Yes & Yes \\
Section FEs & Yes & Yes & Yes \\
\hline \hline
\end{tabular}

Notes: Dependent variables in columns (1) and (3) are indices based on the first principal components of several underlying variables described in the paper. The indices are standardised to mean zero and an SD of one. The dependent variable in column (2) is students' self-reported study hours. All regressions control for gender, age, nationality and a third-order polynomial in GPA. Robust SEs, clustered at the student and course levels, are displayed in parentheses. ${ }^{* * *} p<0.01$, ${ }^{* *} p<0.05,{ }^{*} p<0.1$.

\subsection{Mechanisms}

In this section, we use data from two additional sources to shed light on potential mechanisms that may explain why rank affects performance and choices.

\subsubsection{Evidence from course evaluations}

Our first data source is course evaluations, which are short online surveys that students complete at the end of each teaching period. Using these evaluations, we construct three outcome variables: (i) students' perception of the quality of their section peers, (ii) students' self-reported study hours and (iii) students' perception of the quality of their section instructor. Except for the category of study hours, which is measured based on one survey question, the other outcomes are standardised indices based on several questions (see Online Appendix Table A8 for details). We construct the indices based on the first principal component of the respective questions and standardise each index to mean zero and an SD of one. The outcomes are proxies for several mechanisms that may explain the effect of rank on performance and choices. The perceived quality of peers provides us with indirect information on how students evaluate their peers in relation to their own perceived ability and, therefore, can be seen as a proxy for a student's beliefs. Another important mechanism is effort, for which self-study hours are a proxy. Finally, perceived quality of teachers is informative about potential effects running through teachers' being responsive to a student's rank. For example, students with higher rank may receive more attention from the instructor or perform better if instructors teach to the top of the class.

Table 8 displays the estimated effects of rank on the proxies for mechanisms. Column (1) shows that a higher rank induces students to give a lower rating to their peer interactions in the course. One potential interpretation of this result could be that more highly ranked students view themselves as more able compared to their peers and, consequently, see interactions with less able peers as less fruitful. In column (2), we find a positive, albeit small and statistically insignificant, effect of rank on study hours. This suggests that if the overall effect is driven by effort, it is not driven by the extensive margin, that is, how many hours a student studies. In column (3) we find economically and statistically insignificant effects for teacher evaluations. 
Table 9. Effect of Rank on Expectations and Performance.

\begin{tabular}{lcc}
\hline \hline & $(1)$ & $(2)$ \\
& Std. grade & Std. expected grade \\
\hline Std. rank & $0.0474^{* *}$ & $0.0269^{* *}$ \\
& $(0.017)$ & $(0.011)$ \\
Observations & 2,304 & 1,993 \\
$R^{2}$ & 0.278 & 0.281 \\
Parallel course FEs & Yes & Yes \\
Section FEs & Yes & Yes \\
\hline \hline
\end{tabular}

Notes: The regressions are based on the first-term performance and grade expectations of three incoming cohorts. All regressions include controls for gender, age, nationality, a third-order polynomial in the statistics entry test and the fixed effects listed at the bottom. Expected grades are measured with the question 'What do you think your exam grade will be for the course Quantitative Methods 1?'. Robust SEs, clustered at the student and course levels, are displayed in parentheses. ${ }^{* * *} p<0.01,{ }^{* *} p<0.05,{ }^{*} p<0.1$.

\subsubsection{Direct evidence on beliefs}

Our second data source is a compulsory survey of first-year students that contains more direct evidence on beliefs. The survey was run in three cohorts two weeks after the start of their first teaching period. After taking a compulsory statistics entry test and learning their grade, students had to take a short survey that, among other questions, asked them about their expected grade on the module Quantitative Methods. We use the expected grade as an outcome that proxies for beliefs. We construct a student's rank within their sections in the first teaching period based on their statistics entry score.

The results of this analysis are displayed in Table 9. As a benchmark, column (1) shows the effect of the ordinal rank on standardised grades at the end of teaching period 1. Reassuringly, the effect of the rank based on the statistics score on standardised grades is similar in magnitude to the effect of rank based on GPA in Table 3. In column (2), we estimate the effect of the ordinal rank on expected grades. A one SD increase in the ordinal rank increases expected grades by $4.7 \%$ of an SD, which is about $40 \%$ of the effect of rank on actual grades. This result provides direct evidence that the ordinal rank shapes a student's beliefs, which may in turn affect performance.

These results are in line with earlier work by Elsner and Isphording (2017) and Murphy and Weinhardt (2020). The former showed that an increase in rank by one SD increases students' subject-specific confidence by $6 \%$ of an SD. The latter found that an increase in the percentile rank by 10 percentage points significantly increases the likelihood that a student believes he or she is more intelligent than the average. Compared to these estimates, we find a smaller effect in this paper. Nonetheless, this result corroborates the hypothesis that rank effects operate through a student's self-confidence. ${ }^{16}$

\section{Conclusion}

In this paper, we present evidence that a student's ordinal rank in a peer group affects performance and specialisation choices in college. By exploiting the repeated random assignment of students

\footnotetext{
16 More broadly, these results relate to the literature on the big-fish-in-a-little-pond (BFLP) theory, which has a long tradition in psychology (see Fang et al., 2018 for a systematic review). However, the effect sizes are not readily comparable with the estimated rank effects in Elsner and Isphording (2017) and Murphy and Weinhardt (2020) and related studies. BFLP effects are typically estimated from the negative correlation between own academic self-concept and average peer ability while holding own ability constant. As such, many studies do not explicitly separate the effect of the ordinal rank from the mechanically related confounding effect of average peer quality.
} 
to teaching sections at a Dutch business school, we find that students who, by chance, rank higher in their section perform better in centrally graded exams, are more likely to choose related follow-up courses and have a higher graduation probability. We also document responses to rank changes that are consistent with asymmetric belief updating. Students' performance improves in response to strong increases in their rank while remaining stable in response to strong decreases. Finally, based on survey data, we show that the effect of rank on performance and choices partly operates through shifting expectations. Students who by chance had a higher rank have higher expectations about their future grades.

These findings provide important insights into the decision making of college students. Our results suggest that students - who may be unsure about their relative ability and preparedness for different study specialisations - place considerable weight on comparisons to other students. Their position relative to peers who they currently observe seems to serve as a signal about where they stand in terms of the global ability distribution. Because peers are randomly assigned, this signal carries substantially more noise than signal. Nevertheless, when making important career decisions, students appear to rely on their rank as a heuristic, thereby placing considerable weight on noisy information. A promising avenue for future research is to design interventions that reduce the noise and help students to make better-informed career choices.

University College Dublin, Geary Institute for Public Policy, Ireland, Institute of Labor Economics (IZA), Germany \& CReAM, UK

IZA \& CESifo, Germany

University of Zurich, Switzerland, IZA, CESifo, Germany \& CEPR, UK

Additional Supporting Information may be found in the online version of this article:

\section{Online Appendix \\ Replication Package}

\section{References}

Andersen, S., Ertac, S., Gneezy, U., List, J.A. and Maximiano, S. (2013). 'Gender, competitiveness, and socialization at a young age: evidence from a matrilineal and a patriarchal society', Review of Economics and Statistics, vol. 95(4), pp. $1438-43$.

Arcidiacono, P. (2004). 'Ability sorting and the returns to college major', Journal of Econometrics, vol. 121(1-2), pp. $343-75$.

Arcidiacono, P., Aucejo, E., Maurel, A. and Ransom, T. (2016). 'College attrition and the dynamics of information revelation', Working Paper 222, Economic Research Initiatives at Duke.

Bertoni, M. and Nisticò, R. (2019). 'Ordinal rank and peer composition: two sides of the same coin?', Discussion Paper 12789, Institute of Labor Economics.

Bobba, M. and Frisanco, V. (2016). 'Learning about oneself: the effects of performance feedback on school choice', Working Paper 16-660, Toulouse School of Economics.

Booij, A.S., Leuven, E. and Oosterbeek, H. (2017). 'Ability peer effects in university: evidence from a randomized experiment', Review of Economic Studies, vol. 84(2), pp. 547-78.

Carrell, S.E., Fullerton, R.L. and West, J.E. (2009). 'Does your cohort matter? Measuring peer effects in college achievement', Journal of Labor Economics, vol. 27(3), pp. 439-64.

Carrell, S.E., Sacerdote, B.I. and West, J.E. (2013). 'From natural variation to optimal policy? The importance of endogenous peer group formation', Econometrica, vol. 81(3), pp. 855-82.

Chevalier, A., Gibbons, S., Thorpe, A., Snell, M. and Hoskins, S. (2009). 'Students' academic self-perception', Economics of Education Review, vol. 28(6), pp. 716-27.

Cicala, S., Fryer, R.G. and Spenkuch, J.L. (2018). 'Self-selection and comparative advantage in social interactions', Journal of the European Economic Association, vol. 16(4), pp. 983-1020. 
Cooper, K.M., Krieg, A. and Brownell, S.E. (2018). 'Who perceives they are smarter? Exploring the influence of student characteristics on student academic self-concept in physiology', Advances in Physiology Education, vol. 42(2), pp. 200-8.

Dai, D.Y. and Rinn, A.N. (2008). 'The big-fish-little-pond effect: what do we know and where do we go from here?', Educational Psychology Review, vol. 20(3), pp. 283-317.

De Giorgi, G., Pellizzari, M. and Redaelli, S. (2010). 'Identification of social interactions through partially overlapping peer groups', American Economic Journal: Applied Economics, vol. 2(2), pp. 241-75.

De Giorgi, G. and Pellizzari, M. (2014). 'Understanding social interactions: evidence from the classroom', ECONOMIC JOURNAL, vol. 124(579), pp. 917-53.

Delaney, J. and Devereux, P.J. (2019). 'The effect of high school rank in English and math on college major choice', Discussion Paper 12846, Institute of Labor Economics.

Denning, J.T., Murphy, R. and Weinhardt, F. (2020). 'Class rank and long-run outcomes', Working Paper No. 27468, National Bureau of Economic Research.

Eil, D. and Rao, J.M. (2011). 'The good news-bad news effect: asymmetric processing of objective information about yourself', American Economic Journal: Microeconomics, vol. 3(2), pp. 114-38.

Elsner, B. and Isphording, I.E. (2017). 'A big fish in a small pond: ability rank and human capital investment', Journal of Labor Economics, vol. 35(3), pp. 787-828.

Elsner, B. and Isphording, I.E. (2018). 'Rank, sex, drugs and crime', Journal of Human Resources, vol. 53(2), pp. 356-81.

Epple, D. and Romano, R. (2011). 'Peer effects in education: a survey of the theory and evidence', in (J. Benhabib, A. Bisin and M. Jackson, eds.), Handbook of Social Economics, pp. 1053-163, Amsterdam: North Holland.

Fang, J., Huang, X., Zhang, M., Huang, F., Li, Z. and Yuan, Q. (2018). 'The big-fish-little-pond effect on academic self-concept: a meta-analysis', Frontiers in Psychology, vol 9(18), pp. 15-69.

Feld, J., Salamanca, N. and Zölitz, U. (2020). 'Are professors worth it? The value-added and costs of tutorial instructors', Journal of Human Resources, vol 55(3), pp. 836-63.

Feld, J. and Zölitz, U. (2017). 'Understanding peer effects: on the nature, estimation, and channels of peer effects', Journal of Labor Economics, vol. 35(2), pp. 387-428.

Gill, D., Kissová, Z., Lee, J. and Prowse, V.L. (2019). 'First-place loving and last-place loathing: how rank in the distribution of performance affects effort provision', Management Science, vol. 65(2), pp. 494-507.

Kiessling, L. and Norris, J. (2020) 'The long-run effect of peers on mental health', Discussion Paper 2020/12, Max Planck Institute for Research on Collective Goods.

Kuyper, H., Dijkstra, P., Buunk, A.P. and van der Werf, M.P. (2011). 'Social comparisons in the classroom: an investigation of the better than average effect among secondary school children', Journal of School Psychology, vol. 49(1), pp. 25-53.

Kuziemko, I., Buell, R.W., Reich, T. and Norton, M.I. (2014). 'Last-place aversion: evidence and redistributive implications', Quarterly Journal of Economics, vol. 129(1), pp. 105-49.

Lyle, D.S. (2007). 'Estimating and interpreting peer and role model effects from randomly assigned social groups at West Point', Review of Economics and Statistics, vol. 89(2), pp. 289-99.

Lyle, D.S. (2009). 'The effects of peer group heterogeneity on the production of human capital at West Point', American Economic Journal: Applied Economics, vol. 1(4), pp. 69-84.

Marsh, H.W. (1987). 'The big-fish-little-pond effect on academic self-concept', Journal of Educational Psychology, vol. 79(3), pp. 280-95.

Murphy, R. and Weinhardt, F. (2020). 'Top of the class: the importance of ordinal rank', Review of Economic Studies, vol. 87(6), pp. 2777-826.

Niederle, M. and Vesterlund, L. (2007). 'Do women shy away from competition? Do men compete too much?', Quarterly Journal of Economics, vol. 122(3), pp. 1067-101.

Pagani, L., Comi, S. and Origo, F. (2019). 'The effect of school rank on personality traits', Journal of Human Resources, forthcoming.

Ribas, R., Sampaio, B. and Trevisan, G. (2020). 'Short- and long-term effects of class assignment: evidence from a flagship university in Brazil', Labour Economics, vol. 64(101835), https://doi.org/10.1016/j.labeco.2020.101835.

Sacerdote, B. (2001) 'Peer effects with random assignment: results for Dartmouth roommates', Quarterly Journal of Economics, vol. 116(2), pp. 681-704.

Sacerdote, B. (2011). 'Peer effects in education: how might they work, how big are they, and how much do we know thus far', in (E. Hanushek, S. Machin and L. Woessmann, eds.), Handbook on the Economics of Education, vol. 3, pp. 249-77, Amsterdam: North Holland.

Shue, K. (2013). 'Executive networks and firm policies: evidence from the random assignment of MBA peers', Review of Financial Studies, vol. 26(6), pp. 1401-42.

Stinebrickner, R. and Stinebrickner, T.R. (2012). 'Learning about academic ability and the college dropout decision', Journal of Labor Economics, vol. 30(4), pp. 707-48.

Stinebrickner, R. and Stinebrickner, T.R. (2014). 'A major in science? Initial beliefs and final outcomes for college majors and dropouts', Review of Economic Studies, vol. 81(1), pp. 426-72.

Sutter, M. and Glätzle-Rützler, D. (2014). 'Gender differences in the willingness to compete emerge early in life and persist', Management Science, vol. 61(10), pp. 2339-54. 
Wiswall, M. and Zafar, B. (2015). 'Determinants of college major choice: identification using an information experiment', Review of Economic Studies, vol. 82(2), pp. 791-824.

Zafar, B. (2011). 'How do college students form expectations?', Journal of Labor Economics, vol. 29(2), pp. 301-48. Zimmermann, F. (2020). 'The dynamics of motivated beliefs', American Economic Review, vol. 110(2), pp. 337-61. Zölitz, U. and Feld, J. (2020). 'The effect of peer gender on major choice', Management Science, forthcoming. 